\title{
Botulinum toxin to improve vessel graft patency in cerebral revascularization surgery: report of 3 cases
}

\author{
Ben A. Strickland, MD, ${ }^{1}$ Robert C. Rennert, MD, ${ }^{2}$ Joshua Bakhsheshian, MD, ${ }^{1}$ Sebina Bulic, MD, ${ }^{3}$ \\ Adrian J. Correa, MD, ${ }^{4}$ Arun Amar, MD, ${ }^{1,5}$ Joseph Carey, MD, ${ }^{6}$ and Jonathan J. Russin, MD ${ }^{7}$

\begin{abstract}
Departments of ${ }^{1}$ Neurosurgery, ${ }^{3}$ Neurology, ${ }^{4}$ Pathology, and ${ }^{6}$ Plastic Surgery; ${ }^{5}$ Zilkha Neurogenetic Institute; ${ }^{7}$ Neurorestoration Center, Department of Neurological Surgery, Keck School of Medicine, University of Southern California, Los Angeles; and
\end{abstract} \\ 2Department of Neurosurgery, University of California at San Diego, California
}

\begin{abstract}
Surgical revascularization continues to play an important role in the management of complex intracranial aneurysms and ischemic cerebrovascular disease. Graft spasm is a common complication of bypass procedures and can result in ischemia or graft thrombosis. The authors here report on the first clinical use of botulinum toxin to prevent graft spasm following extracranial-intracranial (EC-IC) bypass. This technique was used in 3 EC-IC bypass surgeries, 2 for symptomatic carotid artery occlusions and 1 for a ruptured basilar tip aneurysm. In all 3 cases, the harvested graft was treated ex vivo with botulinum toxin before the anastomosis was performed. Post-bypass vascular imaging demonstrated patency and the absence of spasm in all grafts. Histopathological analyses of treated vessels did not show any immediate endothelial or vessel wall damage. Postoperative angiograms were without graft spasm in all cases. Botulinum toxin may be a reasonable option for preventing graft spasm and maintaining patency in cerebral revascularization procedures.
\end{abstract}

https://thejns.org/doi/abs/10.3171/2017.9.JNS171292

KEY WORDS botulinum toxin; revascularization; EC-IC bypass; graft patency; vascular disorders

$\mathrm{F}$ IRST described by Yasargil in 1967, extracranial-intracranial (EC-IC) bypass remains a valuable treatment modality for complex cerebral aneurysms and refractory symptomatic vessel occlusions. ${ }^{7,16,18}$ The maintenance of flow is critical to the success of bypass surgery, but it can be complicated by the need for interposition grafts connecting donor and recipient vessels due to the risk of vessel spasm and resultant thrombosis and/or ischemia.

While bypass grafts are typically selected based on flow capacity and size matching to recipient and donor vessels, the spasm risk and patency rates of different grafts are also considered. ${ }^{2}$ Previous studies in the neurosurgical, plastic surgery, and cardiovascular literature have identified strategies to decrease the risk of graft spasm and/or thrombosis, including maintaining an elevated mean arterial pressure and using vasodilators in the immediate postoperative period, devoting attention to atraumatic graft harvests, and using antiplatelet agents. ${ }^{7,9,12,17,21,27-29}$ Ex vivo graft treatments with short-acting vasodilators prior to implantation have also been described, ${ }^{9,21}$ although no definitive spasm prevention strategy exists.

Botulinum toxin (BTX) is a powerful neurotoxin used safely in a multitude of clinical settings for muscle relaxation. ${ }^{23}$ It has also been described for the prevention of arterial graft spasm in preclinical cardiovascular and plastic surgery assessments, ${ }^{6,820,26}$ although no clinical data for this application exist. Herein, we report on the first clinical experience using BTX to prevent graft spasm in 3 patients who underwent EC-IC bypass. We also demonstrate, via histopathological analysis, the absence of any immediate endothelial or vessel wall damage from the BTX treatment.

\section{Methods}

Retrospective analysis of an IRB-approved, prospectively maintained database was performed to identify patients who had undergone EC-IC cerebral bypass surgery using grafts treated with BTX. Recorded information included patient demographics (age, sex), clinical presentation, and surgery performed, as well as imaging and neurological outcomes.

All procedures for vessel harvest and donor site anastomosis were performed by the senior author (J.J.R.) and a plastic surgeon (J.C.). Patients were considered for cerebral revascularization after conservative treatments had failed or if lesions were not amenable to traditional microsurgical or endovascular approaches. The revascularization strategy was planned through collaboration with the plastic surgery and neurosurgical teams. In all cases a descending branch of the lateral circumflex femoral artery

ABBREVIATIONS BTX = botulinum toxin; DLCFA = descending branch of the lateral circumflex femoral artery; EC-IC = extracranial-intracranial; ICA = internal carotid artery; $\mathrm{MCA}=$ middle cerebral artery; $\mathrm{RA}=$ radial artery; $\mathrm{SAH}=$ subarachnoid hemorrhage; $\mathrm{STA}=$ superficial temporal artery.

SUBMITTED May 26, 2017. ACCEPTED September 5, 2017.

INCLUDE WHEN CITING Published online March 2, 2018; DOI: 10.3171/2017.9.JNS171292. 


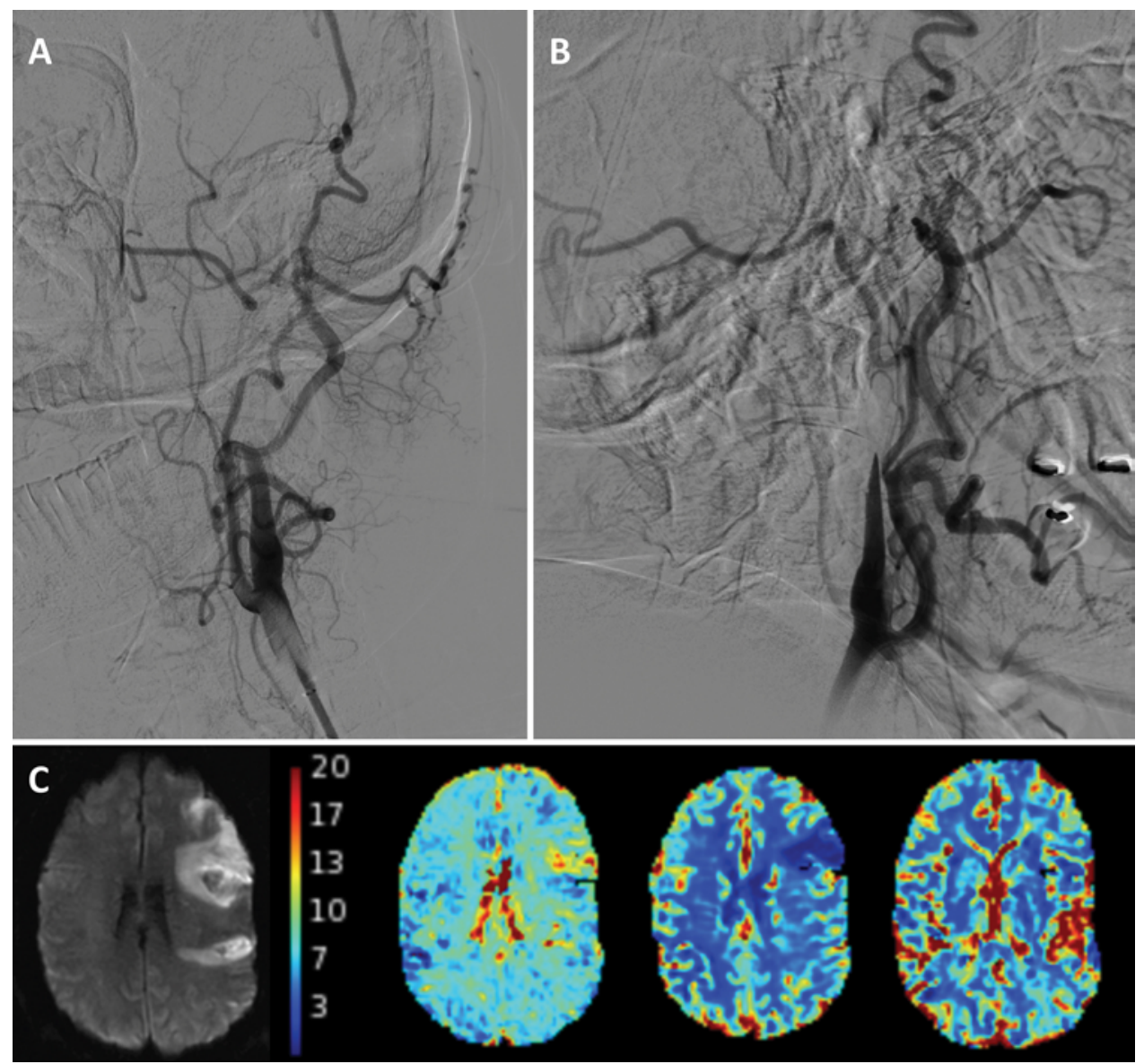

FIG. 1. Case 1. Preoperative workup demonstrated left ICA occlusion with significant penumbral tissue. Lateral (A) and oblique (B) angiograms obtained in a 57-year-old man presenting with acute aphasia and hemiparesis, demonstrating a cervical left ICA occlusion. A CT angiography study (not shown) demonstrated vessel reconstitution beyond the ophthalmic segment. Axial diffusionweighted (left, C) and perfusion-weighted (right, C) MRI studies demonstrated scattered anterior cerebral artery and MCA infarcts with a large ischemic penumbra in the left MCA distribution, as seen by (from left to right) increased mean transit times, decreased cerebral blood flow, and preserved cerebral blood volumes. Figure is available in color online only.

(DLCFA) graft was used as the bypass vessel, which was treated ex vivo with BTX before implantation. A small section of each treated (and untreated in 1 patient) DLCFA graft was collected and sent for histopathological analysis via standard $\mathrm{H} \& \mathrm{E}$ staining.

After the patient's right thigh was prepped and draped, a dissection plane between the rectus femoris and vastus lateralis muscles was developed. The DLCFA was dissected for approximately $10 \mathrm{~cm}$ using 3.0 nylon ties to ligate tributaries. The graft was ligated proximally and distally and then cut sharply and removed from the leg. The adventitia was removed, and the graft was flushed and then soaked using $100 \mathrm{U}$ of BTX type A (Allergan Inc.) in $10 \mathrm{ml}$ of normal saline for approximately 30 minutes. Before the graft was mobilized to the intracranial space, it was flushed with a heparin and milrinone solution, our standard graft irrigation solution consisting of $10,000 \mathrm{U}$ of heparin with $10 \mathrm{mg}$ of milrinone in $1 \mathrm{~L}$ of normal saline.

\section{Results}

Three patients, 2 for symptomatic carotid artery occlu- sions and 1 for a ruptured basilar tip aneurysm, had undergone superficial temporal artery (STA) to middle cerebral artery (MCA) EC-IC bypass surgery utilizing DLCFA grafts treated ex vivo with BTX prior to implantation. The average patient age was 52.6 years, and all 3 patients were male. The bypass procedure was technically successful in all cases. None of the patients exhibited imaging or clinical signs of postoperative graft spasm. Histopathological analysis of the treated vessels demonstrated no endothelial or vessel wall injury.

\section{Case Reports \\ Case 1}

A 57-year-old man presented with the acute onset of dense mixed aphasia and right-sided paresis and was found to have a left internal carotid artery (ICA) occlusion. Preoperative CT angiography demonstrated occlusion of the cervical portion of the ICA with reconstitution beyond the ophthalmic segment (Fig. 1A and B). Perfusion-weighted MRI demonstrated scattered anterior cerebral artery and MCA infarcts with a large ischemic penumbra incorpo- 

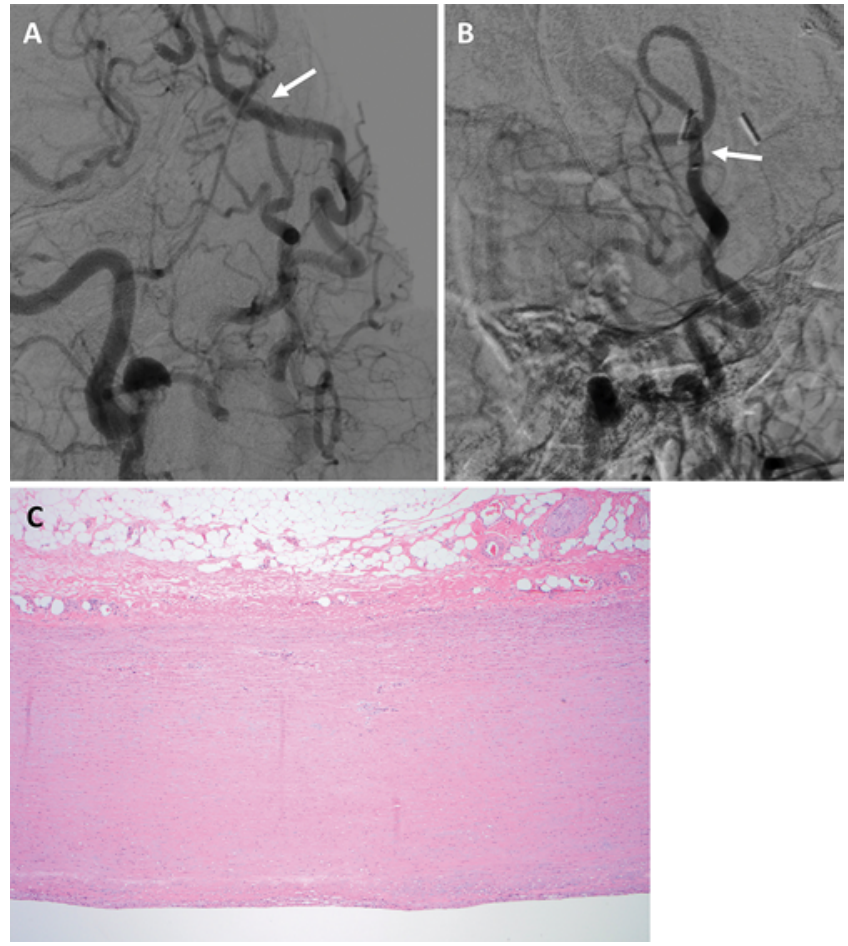

FIG. 2. Case 1. Postoperative imaging and histology demonstrated EC-IC graft health and the absence of spasm following ex vivo BTX treatment. Postoperative day 2 anteroposterior $(\mathbf{A})$ and lateral $(\mathbf{B})$ angiograms demonstrating a patent STA-MCA interposition graft (arrows) without evidence of spasm. Intrinsic left ICA flow is improved in these images because of partial endovascular treatment of the occlusion. A photomicrograph (C) of a portion of the DLCFA graft following BTX treatment demonstrated an intact endothelium and vessel muscular walls, with no structural deformities. $\mathrm{H} \& \mathrm{E}$, original magnification $\times 100$. Figure is available in color online only.

rating the entire left MCA territory (Fig. 1C). An endovascular attempt to open the occluded vessel moderately improved ICA flow but was ultimately unsuccessful. An STA-MCA bypass with a BTX-treated DLCFA graft was performed. Postoperative MRI demonstrated no new ischemia, and angiography showed a patent graft without evidence of spasm (Fig. 2A and B). Histopathological analysis revealed no immediate effects of BTX treatment on the endothelium or vessel wall (Fig. 2C). The patient had an unremarkable postoperative hospital course before discharge to a rehabilitation facility. By the 4.5-month follow-up, he was residing at home, his speech was conversational, and his motor function had improved to being ambulatory without assistance (with stable right-sided upper extremity strength).

\section{Case 2}

A 45-year-old man presented with the acute onset of headaches and was found to have a subarachnoid hemorrhage (SAH) from a ruptured, broad-based, bilobed basilar tip aneurysm (Fig. 3). Angiography demonstrated bilateral carotid arteries that terminated in the ophthalmic arteries, and the intracranial circulation was entirely dependent on the basilar artery. Given the complicated morphology of the basilar tip aneurysm, we anticipated that he would

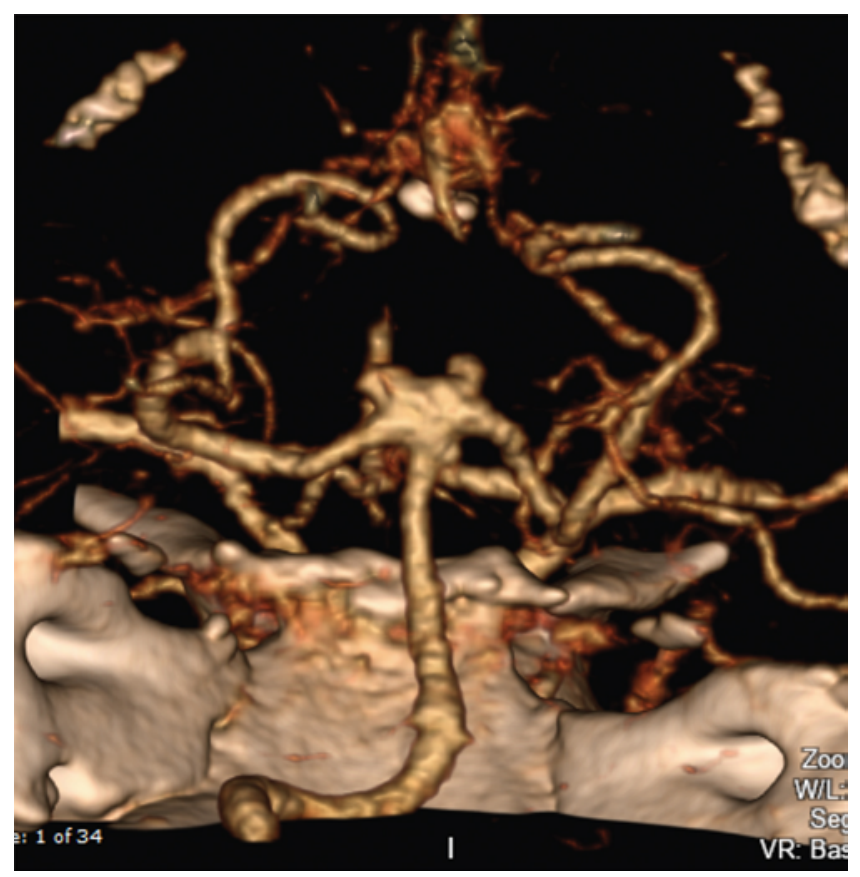

FIG. 3. Case 2. Preoperative vessel imaging demonstrated a large basilar tip aneurysm. CT angiography study obtained in a 45-year-old man following an SAH, demonstrating a broad-based, bilobed basilar tip aneurysm, with the patient's anterior circulation entirely dependent on the posterior communicating arteries. He was treated with an STA-MCA bypass with a BTX-treated DLCFA graft for revascularization of the anterior circulation in conjunction with clip ligation of the basilar tip aneurysm. Figure is available in color online only.

require temporary clipping of the basilar artery. He was, therefore, recommended for revascularization of the anterior circulation in conjunction with clip ligation of the basilar tip aneurysm. He underwent STA-MCA bypass with a BTX-treated DLCFA graft. Immediate postoperative CT angiography and postoperative day 11 angiography demonstrated a patent graft with no evidence of spasm (Fig. 4A and B). Graft histopathology demonstrated no immediate adverse effects of BTX treatment on the endothelium or vessel wall (Fig. 4C-F). The patient had an unremarkable postoperative recovery and was transferred to a rehabilitation facility once medically cleared. By the 2-month follow-up, he was living at home and remained neurologically intact.

\section{Case 3}

A 56-year-old man presented with acute left-sided weakness and was found to have a right ICA occlusion. His CT revealed perfusion deficits, and several attempts to wean him off of vasopressors failed with worsening leftsided weakness to the point of being barely antigravity. He underwent STA-MCA bypass with a BTX-treated DLCFA graft. His postoperative neurological exam was stable with blood pressure normalization. Postoperative CT angiography and conventional angiography demonstrated a patent bypass with no evidence of spasm (Fig. 5A and B) and improved right-sided perfusion. Graft histopathology demonstrated no evidence of endothelial or vessel wall injury 

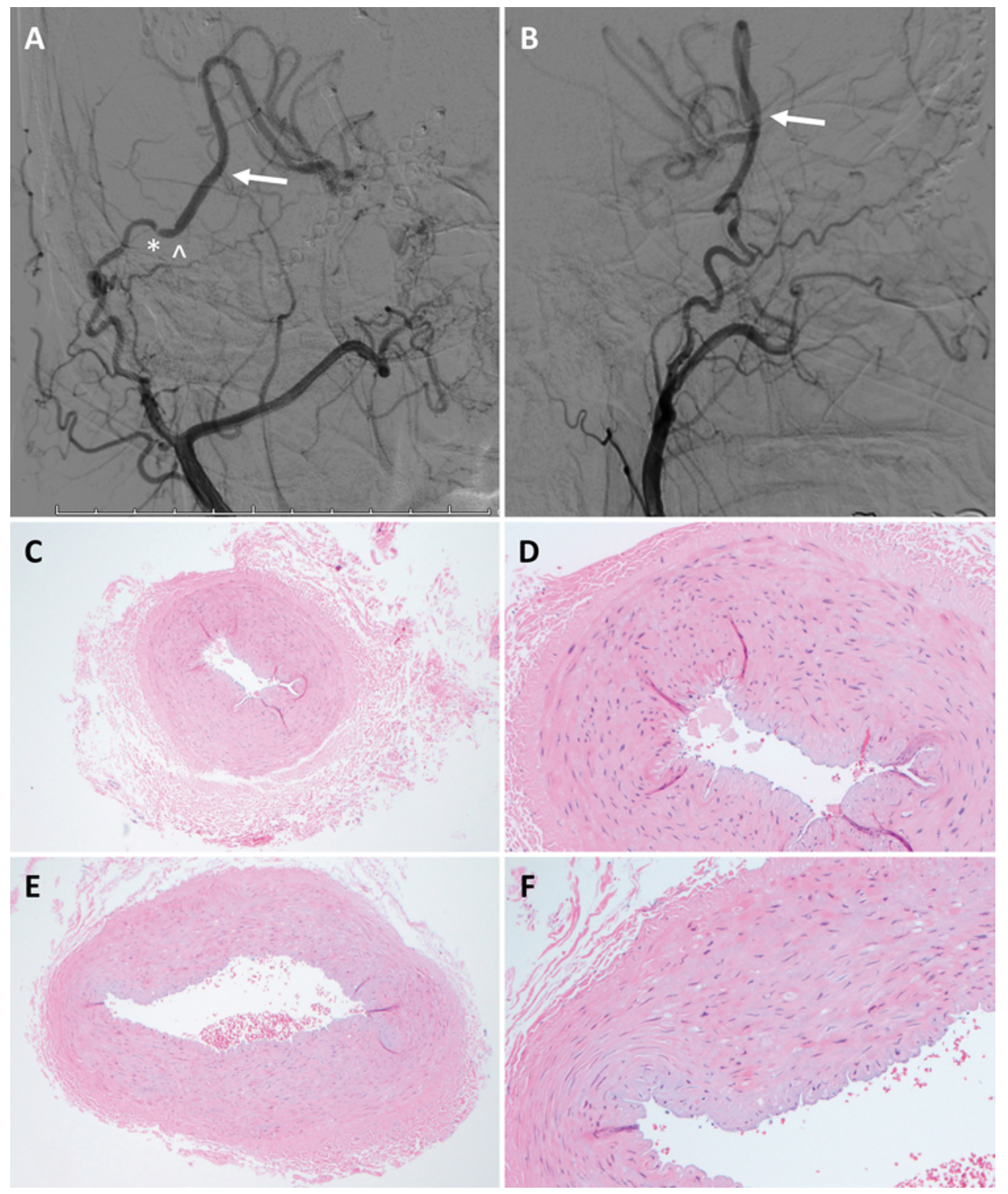

FIG. 4. Case 2. Postoperative angiography and histology demonstrated EC-IC graft health and the absence of spasm following BTX treatment. Postoperative day 11 anteroposterior $(\mathbf{A})$ and lateral $(\mathbf{B})$ angiograms demonstrating a patent STA-MCA with a DLCFA graft (arrows) that had been treated ex vivo with BTX. *Site of spasm on untreated distal STA at the clip site. Beginning of graft. A comparison of low-magnification and high-magnification images of untreated (C and $\mathbf{D}$, respectively) and BTX-treated ( $E$ and $F$, respectively) portions of the DLCFA graft demonstrates integrity of the endothelium and vessel wall and no structural deformities after BTX treatment. Vasodilation was also noted in the treated sample. $\mathrm{H} \& \mathrm{E}$, original magnification $\times 40(\mathrm{C}$ and $\mathrm{E})$, $\times 100(\mathrm{D}$ and $\mathrm{F})$. Figure is available in color online only.

(Fig. 5C and D). His remaining hospital course was unremarkable, and he had improving left-sided strength prior to discharge to a rehabilitation facility. By the 2-week follow-up, he was ambulatory in a rehabilitation facility with continued improvements in left-sided strength.

\section{Discussion}

Ensuring vessel patency is critical to the success of graft-based EC-IC bypass. Graft spasm represents a particularly challenging pathology given its potential to rapidly and severely alter blood flow. Historically, the 2 main options for cerebral bypass grafts have been the radial artery
(RA) and the saphenous vein., ${ }^{2,12,29}$ While there are advantages and disadvantages to both, RA grafts are generally preferred for EC-IC bypass given their higher overall patency rates and better donor-recipient vessel size matching. Nonetheless, RA grafts are at risk for spasm, an extreme smooth muscle-mediated vasoconstrictive response to mechanical or pharmacological stimuli, which can occur in up to $10 \%$ of cases. ${ }^{1,5,7,9}$ Other arterial grafts have also been described, such as the DLCFA graft that was used in the current series because of its closer size match to the donor STA, but are similarly susceptible to spasm.

When spasm occurs, treatment options include systemic anticoagulation, intraarterial injection of the cal- 

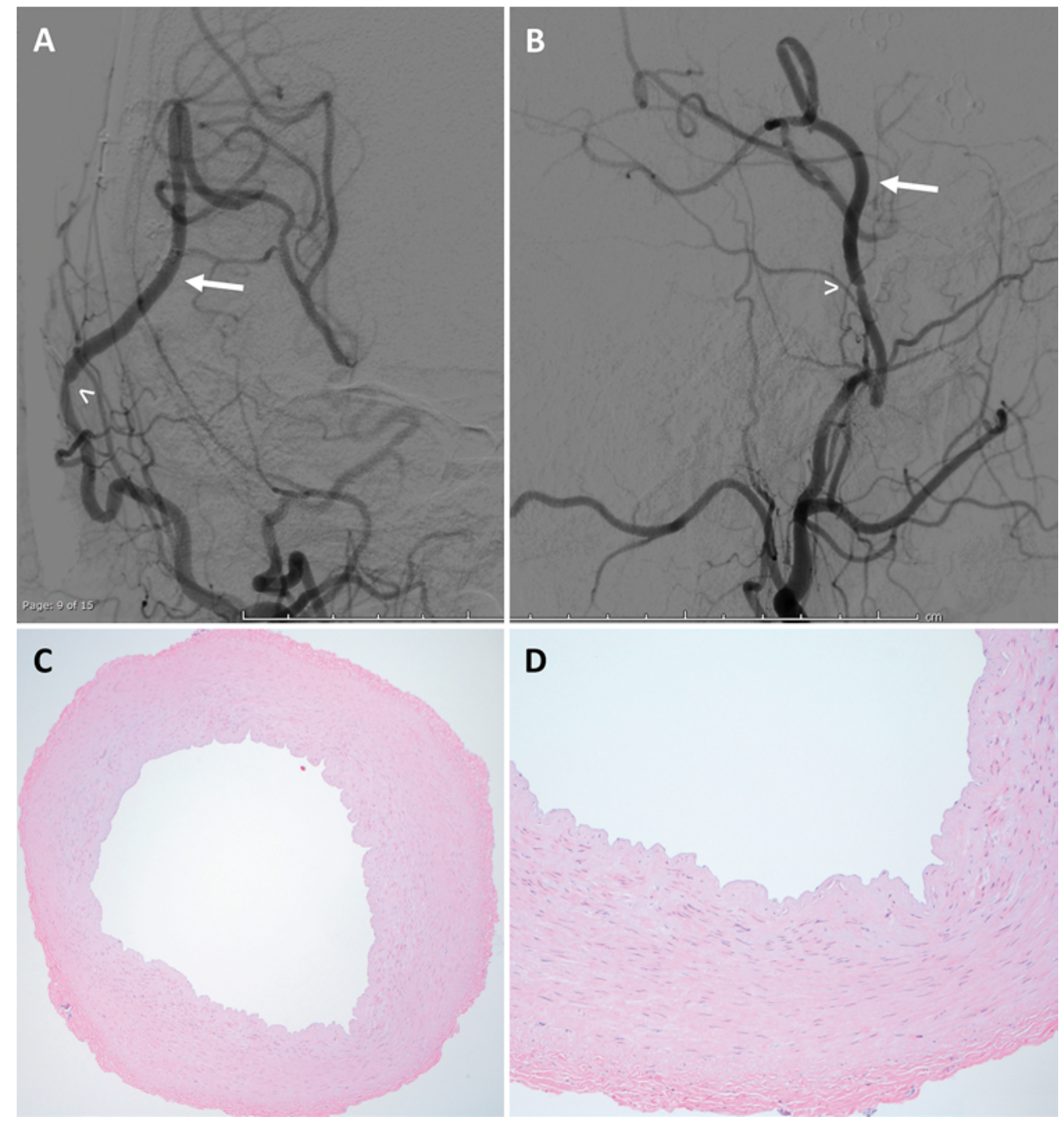

FIG. 5. Case 3. Postoperative angiography and histology in a 56-year-old man treated using an STA-MCA bypass with a BTXtreated DLCFA graft for a progressively symptomatic, pressure-dependent right ICA occlusion. Day 4 postoperative anteroposterior (A) and lateral (B) angiograms demonstrated no spasm and graft patency. Arrows indicate the bypass graft. Site of STA-graft anastomosis. Low-magnification (C) and high-magnification (D) images of a portion of the BTX-treated DLCFA demonstrated no evidence of endothelial or vessel wall injury. $\mathrm{H} \& \mathrm{E}$, original magnification $\times 40$ (C), $\times 100$ (D). Figure is available in color online only.

cium channel blocker verapamil and the antispasmodic papaverine, angioplasty, and local application of vasodilators. ${ }^{14,22}$ However, the prevention of graft spasm is the preferred strategy, and both mechanical and pharmacological prophylactic approaches have been described. As disruptions in the endothelium can lead to the release of spasmogenic agents, or spasmogens, such as endothelin and prostanoids, a meticulous surgical technique and preservation of the endothelium during graft harvest and implantation are important initial strategies for decreasing spasm risk. ${ }^{9,10}$ Preservation of the venae comitantes during harvest, along with both arterial and venous anastomoses, has also been suggested as a method of preserving the viability of tissues immediately surrounding the bypass graft, ${ }^{7}$ potentially decreasing spasm risk by reducing local oxidative stress.

Pharmacological prophylaxis of graft spasm is more robust in other surgical fields and typically involves treatment of the graft with a vasodilator prior to implantation, along with postoperative systemic infusion of vasodilators. Protocols from the cardiovascular literature include ex vivo treatment with a verapamil plus nitroglycerin solution, often followed by the systemic administration of calcium channel blockers with or without long-acting nitrates., ${ }^{9,21}$ Other topical pharmacological agents, such as the synthetic prostacyclin iloprost and diltiazem, have also been explored. ${ }^{25,27}$ However, the half-lives of these therapies are minutes to hours, and efficacy data on these techniques are limited. A uniform ex vivo treatment and postoperative protocol for EC-IC bypass graft spasm prevention does not currently exist.

In this setting, BTX has been suggested as a potentially long-term spasmolytic for arterial grafts. This irreversible toxin, produced by the anaerobic, gram-positive bacterium Clostridium botulinum, consists of 7 distinct serotypes (A-G), with types A and B most often used in the clinical setting. While the primary mechanism of action of all BTX subtypes is through presynaptic cleavage of SNARE 

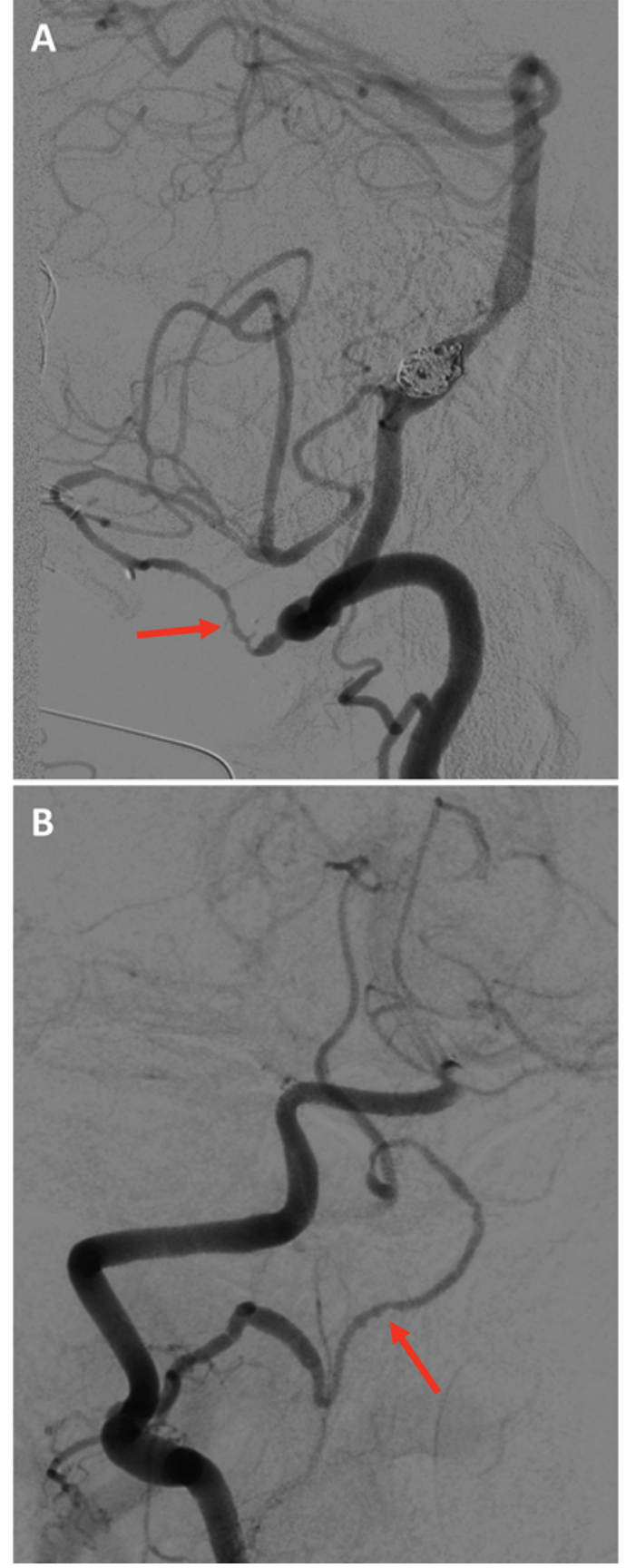

FIG. 6. Angiograms (A and B) from previous cerebral bypass cases using DLCFA grafts, which were harvested in a manner similar to that in the featured cases, but without BTX treatment, demonstrating a susceptibility for postoperative vasospasm (arrows). When such vasospasm occurred, multiple rounds of intraarterial verapamil injections were typically needed for management. Figure is available in color online only.

(soluble NSF attachment protein receptor) proteins important for acetylcholine release into the synaptic terminal, ${ }^{4}$ the mechanism of its effects on arterial graft spasm is less clear, as neuronally mediated spasm of RA or DLCFA grafts is predominantly adrenergic..$^{3,9,11}$ Secondary pathways are thus likely to contribute since the release of vasoconstricting catecholamines is also affected by BTX A-SNARE cleavage, ${ }^{19}$ and BTX $\mathrm{A}$ has been shown to inhibit the presynaptic release of vasoconstricting agents like substance $\mathrm{P}$, as well as to increase the concentration of vasodilating calcitonin-related peptides. ${ }^{13,30}$ Botulinum toxin $\mathrm{C}$ has also been shown to block the GTP-dependent phosphorylation of myosin light chains in vascular smooth muscle, inhibiting constriction. ${ }^{20,24}$ These mechanistic effects are probably occurring in the setting of neuronal hyperactivity proposed to result from surgical denervation. ${ }^{1}$

To date, assessments of BTX for graft spasm prevention have been limited to preclinical cardiovascular and plastic surgery studies. In these works, in vivo rat perivascular pretreatments with BTX B augmented microvessel diameter prior to anastomosis, ${ }^{26}$ and ex vivo treatment of rat aortas with BTX C resulted in the complete loss of adrenergic muscle contraction through the 2-hour study end point (significantly longer than the effect of papaverine). ${ }^{20}$ In vivo perivascular pretreatment with BTX A was also shown to increase vessel diameter and decrease short-term thrombosis rates in rat and rabbit micro-anastomosis models. ${ }^{6,8}$ The arterial wall was not affected by the BTX treatment in any of these studies, and all in vivo treatments were well tolerated.

Thus, the present series represents the first clinical use of BTX for the prevention of arterial graft spasm and provides preliminary evidence for the safety and efficacy of this approach. The impetus for BTX use came from previous cases of severe spasm with DLCFA grafts at our institution, despite a meticulous surgical technique and postoperative blood flow optimization (Fig. 6). Following the ex vivo application of BTX A prior to DLCFA graft implantation in the featured cases, none of the patients exhibited either clinical or radiographic evidence of graft spasm over the short-term to midterm follow-up. As most severe arterial graft spasms occur within the first few days after implantation, ${ }^{10,15}$ delayed spasm in these patients is unlikely. Botulinum toxin A was chosen for application given its extensive clinical safety profile, ${ }^{23}$ and histological analysis of the treated arteries revealed no short-term adverse effects on the endothelium or vessel wall. All 3 patients also had uneventful postoperative and outpatient courses. These data support the utility of BTX treatment for the prevention of arterial graft spasm for cerebral and other bypass applications.

\section{Conclusions}

Ex vivo BTX treatment represents an appealing method for the long-term prevention of bypass graft spasm. Initial cases have not revealed any clinical safety concerns, and radiographic appearances have been markedly improved compared with prior clinical experience. Further data are needed to elucidate the role of BTX treatment in revascularization procedures.

\section{References}

1. Acar C, Jebara VA, Portoghese M, Beyssen B, Pagny JY, Grare P, et al: Revival of the radial artery for coronary artery bypass grafting. Ann Thorac Surg 54:652-660, 1992

2. Baaj AA, Agazzi S, van Loveren H: Graft selection in cerebral revascularization. Neurosurg Focus 26(5):E18, 2009

3. Baikoussis NG, Papakonstantinou NA, Apostolakis E: Radial artery as graft for coronary artery bypass surgery: Advan- 
tages and disadvantages for its usage focused on structural and biological characteristics. J Cardiol 63:321-328, 2014

4. Binz T, Sikorra S, Mahrhold S: Clostridial neurotoxins: mechanism of SNARE cleavage and outlook on potential substrate specificity reengineering. Toxins (Basel) 2:665682,2010

5. Carpentier A, Guermonprez JL, Deloche A, Frechette C, DuBost C: The aorta-to-coronary radial artery bypass graft. A technique avoiding pathological changes in grafts. Ann Thorac Surg 16:111-121, 1973

6. Clemens MW, Higgins JP, Wilgis EF: Prevention of anastomotic thrombosis by botulinum toxin $\mathrm{A}$ in an animal model. Plast Reconstr Surg 123:64-70, 2009

7. El Tecle NE, Zammar SG, Hamade YJ, Ahmadieh TYE, Aoun RJN, Nanney AD, et al: Use of a harvested radial artery graft with preservation of the vena comitantes to reduce spasm risk and improve graft patency for extracranial to intracranial bypass: technical note. Clin Neurol Neurosurg 142:65-71, 2016

8. Fathi M, Fathi H, Mazloumi M, Khalilzadeh O, Amanpour S, Meysamie A, et al: Preventive effect of botulinum toxin A in microanastomotic thrombosis: a rabbit model. J Plast Reconstr Aesthet Surg 63:e720-e724, 2010

9. He GW: Arterial grafts: clinical classification and pharmacological management. Ann Cardiothorac Surg 2:507-518, 2013

10. He GW, Taggart DP: Spasm in arterial grafts in coronary artery bypass grafting surgery. Ann Thorac Surg 101:12221229,2016

11. He GW, Yang CQ: Characteristics of adrenoceptors in the human radial artery: clinical implications. J Thorac Cardiovasc Surg 115:1136-1141, 1998

12. Houkin K, Kamiyama H, Kuroda S, Ishikawa T, Takahashi A, Abe H: Long-term patency of radial artery graft bypass for reconstruction of the internal carotid artery. Technical note. J Neurosurg 90:786-790, 1999

13. Ishikawa H, Mitsui Y, Yoshitomi T, Mashimo K, Aoki S, Mukuno K, et al: Presynaptic effects of botulinum toxin type A on the neuronally evoked response of albino and pigmented rabbit iris sphincter and dilator muscles. Jpn J Ophthalmol 44:106-109, 2000

14. Liu JK, Couldwell WT: Intra-arterial papaverine infusions for the treatment of cerebral vasospasm induced by aneurysmal subarachnoid hemorrhage. Neurocrit Care 2:124-132, 2005

15. Lorusso R, Crudeli E, Lucà F, De Cicco G, Vizzardi E, D'Aloia A, et al: Refractory spasm of coronary arteries and grafted conduits after isolated coronary artery bypass surgery. Ann Thorac Surg 93:545-551, 2012

16. Low SW, Teo K, Lwin S, Yeo LL, Paliwal PR, Ahmad A, et al: Improvement in cerebral hemodynamic parameters and outcomes after superficial temporal artery-middle cerebral artery bypass in patients with severe stenoocclusive disease of the intracranial internal carotid or middle cerebral arteries. J Neurosurg 123:662-669, 2015

17. Matano F, Murai Y, Tateyama K, Tamaki T, Mizunari T, Matsukawa H, et al: Long-term patency of superficial temporal artery to middle cerebral artery bypass for cerebral atherosclerotic disease: factors determining the bypass patent. Neurosurg Rev 39:655-661, 2016

18. Matsukawa H, Tanikawa R, Kamiyama H, Tsuboi T, Noda $\mathrm{K}$, Ota N, et al: Risk factors for neurological worsening and symptomatic watershed infarction in internal carotid artery aneurysm treated by extracranial-intracranial bypass using radial artery graft. J Neurosurg 125:239-246, 2016

19. Morris JL, Jobling P, Gibbins IL: Botulinum neurotoxin A attenuates release of norepinephrine but not NPY from vasoconstrictor neurons. Am J Physiol Heart Circ Physiol 283:H2627-H2635, 2002

20. Murakami E, Iwata H, Imaizumi M, Takemura H: Prevention of arterial graft spasm by botulinum toxin: an in-vitro experiment. Interact Cardiovasc Thorac Surg 9:395-398, 2009

21. Myers MG, Fremes SE: Prevention of radial artery graft spasm: a survey of Canadian surgical centres. Can J Cardiol 19:677-681, 2003

22. Natarajan SK, Hauck EF, Hopkins LN, Levy EI, Siddiqui $\mathrm{AH}$ : Endovascular management of symptomatic spasm of radial artery bypass graft: technical case report. Neurosurgery 67:794-798, 2010

23. Naumann M, Jankovic J: Safety of botulinum toxin type A: a systematic review and meta-analysis. Curr Med Res Opin 20:981-990, 2004

24. Noda M, Yasuda-Fukazawa C, Moriishi K, Kato T, Okuda T, Kurokawa K, et al: Involvement of rho in GTP gamma Sinduced enhancement of phosphorylation of $20 \mathrm{kDa}$ myosin light chain in vascular smooth muscle cells: inhibition of phosphatase activity. FEBS Lett 367:246-250, 1995

25. Ozdemir C, Ikizler M, Besogul Y, Karakaya A, Sirmagul B: An alternative agent for radial arterial graft spasm: application of topical iloprost. Scand Cardiovasc J 41:201-206, 2007

26. Park BY, Kim HK, Kim WS, Bae TH: The effect of botulinum toxin B pretreatment to the blood flow in the microvascular anastomosis. Ann Plast Surg 72:214-219, 2014

27. Rosenfeldt FL, He GW, Buxton BF, Angus JA: Pharmacology of coronary artery bypass grafts. Ann Thorac Surg 67:878888, 1999

28. Sia SF, Qian Y, Zhang Y, Morgan MK: Mean arterial pressure required for maintaining patency of extracranial-to-intracranial bypass grafts: an investigation with computational hemodynamic models-case series. Neurosurgery 71:826831,2012

29. Sundt TM III, Sundt TM Jr: Principles of preparation of vein bypass grafts to maximize patency. J Neurosurg 66:172180,1987

30. Tarabal O, Calderó J, Ribera J, Sorribas A, López R, Molgó $\mathrm{J}$, et al: Regulation of motoneuronal calcitonin gene-related peptide (CGRP) during axonal growth and neuromuscular synaptic plasticity induced by botulinum toxin in rats. Eur $\mathbf{J}$ Neurosci 8:829-836, 1996

\section{Disclosures}

The authors have no conflicts of interest.

\section{Author Contributions}

Conception and design: Strickland, Rennert, Bakhsheshian, Bulic, Correa, Russin. Acquisition of data: Strickland, Rennert, Bakhsheshian, Bulic, Russin. Analysis and interpretation of data: Strickland. Drafting the article: Strickland, Rennert, Bakhsheshian, Correa, Carey, Russin. Critically revising the article: Strickland, Rennert, Bakhsheshian, Correa, Amar, Carey, Russin. Reviewed submitted version of manuscript: Strickland, Rennert, Bakhsheshian, Bulic, Correa, Amar, Carey, Russin. Approved the final version of the manuscript on behalf of all authors: Strickland. Statistical analysis: Strickland. Administrative/technical/ material support: Strickland. Study supervision: Strickland.

\section{Correspondence}

Ben A. Strickland: Keck School of Medicine of the University of Southern California, Los Angeles, CA. ben.strickland@med. usc.edu. 